\title{
Post-dural Puncture Headache in the Obstetric Patient: Needle Size, Number of Dural Puncture and Timing of Ambulation
}

\author{
Sousan Rasooli ${ }^{1}$, Farnaz Moslemi ${ }^{1 *}$, Ali Baybordi ${ }^{2}$
}

\begin{abstract}
Objectives: This prospective study compared the incidence of post-dural puncture headache (PDPH) in obstetric patients undergoing spinal anesthesia for caesarean section from April 2012 to April 2013 in one year. We also evaluated the relationship between needle size, number of dural punctures, timing of ambulation and PDPH after cesarean section.

Materials and Methods: A total of 319 American Society of Anesthesiologists (ASA) I-II full term pregnant women, scheduled for caesarean section under spinal anesthesia from April 2012 to April 2013 were evaluated. Spinal anesthesia was performed with hyperbaric bupivacaine plus fentanyl $10 \mu \mathrm{g}$, from L3-4 intervertebral space. We recorded the number of attempts for spinal anesthesia, and the timing of ambulation. Each patient was monitored every day for 4 days following caesarean section. Frequency and severity of PDPH were recorded. SPSS 16 was used for data analysis.

Results: Needles used were 25G Quincke spinal needle in 243 patients (76.2\%) and 27G Quincke spinal needle in 76 patients (21.9\%). Of 319 patients, there were 315 (95.6\%) in the late ambulation group and $14(4.4 \%)$ in the 6 hour bed rest group. In this study only one patient had the classic symptoms of PDPH, whose spinal block were performed with 25G Quincke spinal needle by residents with more than 2 attempts of lumbar puncture (LP). Severe PDPH was not observed in 27G Quincke group.

Conclusion: Although our study was performed in a teaching hospital with more residents of anesthesia attempting the procedure, the incidence of PDPH was lower in this study as compared to other studies. This study also concluded that needle size and early ambulation may have some effect on the incidence and characteristics of PDPH.

Keywords: Caesarean, Spinal anesthesia, Post-dural puncture headache
\end{abstract}

\section{Introduction}

Spinal anesthesia is often the preferred technique of anesthesia for cesarean delivery. It is a simple procedure with rapid onset and deep sensory block effect that produces excellent operating conditions (1). As a complication of spinal anesthesia, post-dural puncture headache (PDPH) is caused by the needle penetration of the dura matter and loss of cerebrospinal fluid (CSF). During the postpartum period the obstetric patient with $\mathrm{PDPH}$ is usually aware that her headache is iatrogenic and she may become depressed, resentful and/or angry (2-4). Also because of the headache the care of the newborn and the relationship with other family members may be affected. Thus, it is important to explain clearly to her about the reason of the headache, the expected time course and the available treatment (4).

PDPH is defined as a bilateral headache that is related to position. It is especially improved during recumbence and worsened in the upright position of the body. This headache can be excruciating and intolerable. PDPH is usually managed successfully with an epidural blood patch (EBP). Certain factors that may affect the incidence of PDPH include age, gender, pregnancy, history of PDPH, shape of needle tip, size of needle, needle bevel orientation to dural fibers, midline vs lateral lumber puncture (LP) approach, number of LPs, and clinical experience of the operator (5-7). Although, continuous spinal technique and timing of patient's ambulation does not increase the incidence of PDPH (8), but some data indicate that early ambulation may actually decrease its incidence $(9,10)$.

The optimum needle sizes for spinal anesthesia are probably the 25G, 26G, and $27 \mathrm{G}$ needles $(11,12)$. An addendum to the AAN (American Academy of Neurology) practice guideline supported the use of $22 \mathrm{G}$ needles. Nevertheless a case series where $25 \mathrm{G}$ needles were used successfully was also reported (13). If we used smaller diameter needle puncture for subarachnoid block decreased the risk of PDPH. However these needles, especially in the hands of inexperienced operators, are technically difficult to use and are associated with a lower success rate in the spinal 
anesthesia. This is because dural puncture secondary to the slow flow through a small needle is not recognizable and may lead to multiple and repeated puncture attempts. Improvements in design of the needles have lead to a significant decline in the incidence of PDPH (12). Still, $\mathrm{PDPH}$ is a debilitating complication of needle insertion into the subarachnoid space. The incidence of headache after spinal anesthesia varies greatly between studies.

This prospective study was designed to evaluate the frequency and severity of PDPH in patients undergoing elective or emergency cesarean section with spinal anesthesia and also to find the association of needle size, number of attempts and early ambulation as well as the experts who perform spinal anesthesia with PDPH.

\section{Materials and Methods}

In this study, 319 American Society of Anesthesiologists physical status classification (ASA) I-II patients who underwent anesthesia for cesarean section in the Women Teaching hospital of Tabriz University of Medical Sciences, were assessed. The study period extended from April 2012 to April 2013. A total of 323 patients were allocated to the study and finally 243 patients followed-up and analyzed for the study. Once in the operation room, the patients were placed in supine position and by putting a wedge under the right hip were positioned at left lateral $20^{\circ}$. A pulse oximeter, three lead Electrocardiography (ECG) and an automated noninvasive arterial blood pressure monitors were used. Mean arterial pressure, baseline systolic and diastolic blood pressures and heart rate were recorded.

Spinal blocks were performed by three anesthesiologists and a group of anesthesia residents under supervision of an attending anesthesiologist. Two other trained investigators who were blinded to the intraoperative events, conducted the post operative follow-up. During the postoperative interview, all patients were informed about possible risk of developing a PDPH. The patients were hydrated with 500-1000 $\mathrm{ml}$ of Ringer's lactate before the induction of anesthesia. Spinal anesthesia was performed by 25 gauge or 27G Quincke needles, at the L3-L4, or L4-L5 interspaces with the patients in the sitting position. All of the patients received a standard local anesthetic consisting of hyperbaric Bupivacaiene $0.5 \% 12 \mathrm{mg}$, plus fentanyl 15 $\mu \mathrm{g}$ that was injected over $20-30$ seconds. Then the patients were placed in supine position with the wedge under the right hip. Oxygen was given via a facemask at a rate of 5 liters/min.

The number of subarachnoid block attempts was noted. Ephedrine $5 \mathrm{mg}$ IV or phenylephrine 50-100 $\mu \mathrm{g}$ IV was given for hypotension, and repeated as needed, along with additional Ringer solution infusion. Maternal bradycardia was treated with atropine $0.5 \mathrm{mg}$ IV. A T4-T6 sensory block level was obtained before surgical incision. With the bevel of the cutting needles (Quincke) facing parallel to the direction of the dual fibres, Quinckes were introduced. A staff anesthesiologist closely supervised all the procedures. Routine monitoring included noninvasive ar- terial blood pressure and ECG. Also $\mathrm{SaO} 2$ was monitored in all patients during surgery and recovery period. blood pressure was measured every 2 minutes. and then every five min. until the end of surgery. Immediately after the delivery the operation table was removed and lateral tilt. Patients were observed in the recovery until 1 hour after operation, and after obtained the release criteria from recovery unit, they were returned to the obstetrics ward. Patients were placed in $30^{\circ}$ semi-sitting position for 24 hours and were ambulated according to the surgeon's order. All data including maternal age, height, weight, the size of needle, operator training level and the timing of ambulation were recorded.

In the postoperative period all patients were seen daily by a resident or staff physician other than the physician who performed the spinal anesthesia. The resident or staff physician who was not knowing the size of needle used and questioned the patients for the presence of any headache and/or any symptoms such as nausea, vomiting, neck redur, tinnitus and blurred vision. A frontal or occipital headache at the sitting posture and relived with supine posture was assumed as PDPH. The severity of PDPH was graded as mild (no limitation of activity, no treatment required), moderate (limited actively, regular analgesic required) and severe (anorexic, confined to bed, unable to feed the baby) (12). When a patient complained of frontal or occipital headache, she was monitored daily until she was discharged from the hospital. All patients were called, one week later to evaluate for any signs or symptoms of a delayed-onset headache. Patients that had headache were questioned regarding the duration of the headache and the response to treatment. The PDPH was initially treated conservatively with bed rest, hydration, oral analgesics and finally with EBP as needed.

All data were recorded and statistical analysis was performed using SPSS 16. Quantitative variables were expressed as mean and standard deviation (SD), while qualitative variables were expressed as percentage using $t$ test.

\section{Results}

We studied 319 women, aged between 21-42 years, and ASA physical status I-II (290 and 29, respectively) who underwent caesarean section, during 1 year at Alzahra Teaching hospital as shown in the study diagram (Consort flow diagram). Demographic data of the patients including age, weight, height, and operation time are shown in Table1.

Totally 83 (26\%) patients were underwent spinal anesthesia by experienced anesthesiologists and 236 (74\%) patients by residents of anesthesia. $212(66.5 \%)$ patients had one attempt at LP and 107 patients had 2 or more attempts (Table 2).

Hemodynamic changes during surgery including systolic, diastolic, mean arterial pressure, heart rate, and $\mathrm{SaO} 2$ were recorded. Ephedrine in $22.9 \%$ and phenylephrine in $11.9 \%$ of patients were used. There were 6 patients with headache. Three patients were in 25G Quincke group, and 3 patients in 27G Quincke group. Two patients with head- 
Table 1. Demographic Distribution

\begin{tabular}{lccc}
\hline & Mean & SD & Variance \\
\hline Age $(\mathrm{y})$ & 28.66 & 5.328 & 28.388 \\
Weight $(\mathrm{kg})$ & 78.12 & 11.746 & 137.971 \\
Height $(\mathrm{cm})$ & 165.45 & 85.266 & 7270.236 \\
Duration of operation $(\mathrm{min})$ & 48.44 & 6.0415 & 36.500 \\
\hline
\end{tabular}

Table 2. Distribution of Patients According to Spinal Block

\begin{tabular}{lcc}
\hline & No. of Patients & $\%$ \\
\hline Injection by anesthesiologist & 83 & 26.0 \\
Injection by resident & 236 & 74.0 \\
Needle size & & \\
$25 G$ & 243 & 76.2 \\
$27 G$ & 76 & 23.8 \\
No. of attempts & & \\
1 & 212 & 66.5 \\
$\geq 2$ & 107 & 34.5 \\
Ambulation time & & \\
$\leq 6$ h & 1 & 4.4 \\
$\geq 6$ h & 5 & 95.6 \\
\hline
\end{tabular}

ache had one attempt at LP and 4 patients had 2 or more attempts. There were 4 patients with headache at 24 hours after LP and in 2 patients PDPH started within 48 hours after LP.

There were 4 patients with mild headache which occurred in the first 24 hours and became better gradually in the following days. 25G Quincke spinal needle was used in 2 cases, and 27G Quincke spinal needle in 2 patients. Also there was one patient in the 25G Quincke group that had moderate headache occurring in the first 48 hours. These patients, were treated with bed rest, higher fluid intake and analgesics (oral paracetamol).

Severe PDPH was not observed in 27G Quincke group. Only one patient had the classic symptoms of PDPH. Spinal block were performed with 25G Quinck needle by residents of anesthesia with more than two attempts. The occurrence of PDPH was 48 hours after LP, and the patients had late ambulation (12 hours after LP).

There was only one patient with headache in early ambulation group ( $<6$ hours) and 5 patients were in late ambulation group ( $>6$ hours) (Table 3 ).

Overall, patients with PDPH were treated by bed rest, higher fluid intake, analgesics and avoidance of straining. None of patients in this study, required EBP, which is the definitive treatment in refractory cases.

\section{Discussion}

More than one hundred years have passed since the initial description of PDPH. Nevertheless, PDPH still fascinates anaesthesiologists and many studies have been published describing its pathophysiology, prevention and treatment $(2-4,10,13,14)$.

The pathophysiology of PDPH is based on the fact that persistent leakage of CSF through the hole made by the spinal or epidural needle decreases the volume and/or pressure of CSF. This ultimately results in shift of the intracranial contents and traction on pain sensitive structures. Also sudden decrease in CSF volume may activate adenosine leading to arterial and venous vasodilatation and subsequently clinical symptoms of PDPH (10). Incidence of PDPH is affected by certain factors such as age,

Table 3. Number of Patients With PDPH at Different Times According to Number Of Dural Puncture, Needle Size, Ambulation Time and Person Who Performed the Block

\begin{tabular}{|c|c|c|c|c|c|c|c|c|}
\hline Risk Factor & $\begin{array}{c}\text { During } \\
\text { Surgery (No.) }\end{array}$ & $\begin{array}{c}\text { Recovery } \\
\text { (No.) }\end{array}$ & $\begin{array}{c}6 \text { h late } \\
\text { (No.) }\end{array}$ & $\begin{array}{c}24 \mathrm{~h} \text { Later } \\
\text { (No.) }\end{array}$ & $\begin{array}{c}48 \mathrm{~h} \\
\text { Later (No.) }\end{array}$ & $\begin{array}{c}3 \text { days } \\
\text { Later(n) }\end{array}$ & $\begin{array}{c}4 \text { days } \\
\text { Later (No.) }\end{array}$ & $\begin{array}{c}5 \text { days } \\
\text { Later (No.) }\end{array}$ \\
\hline \multicolumn{9}{|l|}{ Number of punctures } \\
\hline 1 & 0 & 2 & 1 & 1 & 1 & 0 & 0 & 0 \\
\hline 2 & 0 & 0 & 1 & 1 & 0 & 0 & 0 & 0 \\
\hline 3 & 0 & 0 & 0 & 1 & 0 & 0 & 0 & 0 \\
\hline 4 & 0 & 0 & 0 & 0 & 0 & 0 & 0 & 0 \\
\hline 5 & 1 & 1 & 2 & 1 & 1 & 0 & 0 & 0 \\
\hline Total & 1 & 3 & 4 & 4 & 2 & 0 & 0 & 0 \\
\hline \multicolumn{9}{|l|}{ Ambulation time } \\
\hline$<6 \mathrm{~h}$ & 0 & 0 & 1 & 0 & 0 & 0 & 0 & 0 \\
\hline$>6 \mathrm{~h}$ & 1 & 3 & 3 & 4 & 1 & 0 & 0 & 0 \\
\hline \multicolumn{9}{|l|}{ Needle size } \\
\hline $25 G$ & 1 & 3 & 4 & 2 & 1 & 0 & 0 & 0 \\
\hline $27 G$ & 0 & 0 & 0 & 2 & 1 & 0 & 0 & 0 \\
\hline \multicolumn{9}{|l|}{ Person } \\
\hline Anesthesiologist & 0 & 0 & 0 & 1 & 1 & 0 & 0 & 0 \\
\hline Resident of anesthesia & 1 & 3 & 4 & 3 & 1 & 0 & 0 & 0 \\
\hline
\end{tabular}


gender, pregnancy, needle size and type.

In our study, the incidence of PDPH was $1.27 \%$ with 25G Quinck needles which is lower than the incidence of PDPH reported in other studies, but it was 3.82\% with $27 \mathrm{G}$ Quinck needles, which is higher in comparison to some other reports.

As all the patients of this study were in the same gender and age population group, and also similar needle types (Quincke) were used, thus it appears that needle size and patient ambulation did affect the occurrence and severity of PDPH.

In the present study, there were 4 patients with non-specific mild headache 6 hours postoperatively, and were not included in PDPH category. However, there were 6 patients with headache 24-48 hours after surgery; 3 of 243 (1.23\%) with 25G Quincke needle and 3 of 76 (3.94\%) with 27G (Quincke) needle.

Data from Turnbull and Shepherd (4) have shown that the incidence of $\mathrm{PDPH}$ is $40 \%$ with $20 \mathrm{G}$; $3 \%-25 \%$ with $25 \mathrm{G}$; $1.5(5.6 \%)$ with $27 \mathrm{G}$, and less than $2 \%$ with $29 \mathrm{G}$ Quinck needles.

So, Small diameter needles decrease the risk of PDPH. However these needles are technically difficult to use, especially in an inexperienced hands, and are associated with lower success rate (5). This is because of difficulty in identifying dural puncture secondary to slow CSF flow through a small needle, resulted to repeated multiple puncture attempts (15). However,the incidence of PDPH with 22- gague Whitacre (non cutting) needle is lower than 27-gauge Quincke (cutting) needle (5).

In the present study all of the 3 cases with headache (in 27G Quincke) underwent spinal block with more than two attempts. One patient who had the classic symptoms of PDPH (in 25G Quincke) underwent spinal block with residents of anesthesia with more than two attempts.

In one study with Shah et al (15), 75 patients were studied according to the size and shape of 25G Quinke, 27G Quincke, and 27G Whitacre neddles. The incidence and severity of PDPH, 9 patients had postoperative headache. In their study, of 75 patients, 9 had postoperative headache. The incidence of PDPH was $20 \%, 12.5 \%$ and $4.5 \%$ with the needle type used, respectively.

In another study Sheikh and colleagues compared the frequency and severity of PDPH in obstetric patients using 25G Quincke, 27G Quincke and 27G Whitacre spinal needles. They reported the frequency of PDPH following the use of, and $25 \mathrm{G}$ Whitacre spinal needles as $8.3 \%, 3.8 \%$ and $2.0 \%$, respectively (12). They concluded that $27 \mathrm{G}$ Whitacre spinal needles reduce the frequency of PDPH. However in their study, the numbers of attempt for spinal blocks were limited to one but in our study the number of attempts and the person who performed the block are variable and assessed as the affecting risk factors.

The frequency and severity of PDPH in our study were lower than the aforementioned studies, and is near to standard rate reported, and it may be related to the operator experience and the technique of this procedure such as the introducing and with-drawing of the needle with its bevel parallel to the direction of the dural fibers.

Tajavanija and colleagues studied and compared the prevalence of PDPH between 6 hour-supine recumbence and early ambulation in two groups of patients. They did not find difference in the characteristics and prevalence of PDPH between 6 hour-supine recumbence and early ambulation (9).

In this study only one patient in early ambulation group had severe headache. Timing of ambulation in 5 patients with mild headache was more than 6 hours, and ambulation time of patient with sever PDHP was 12 hours after the end of surgery. Although the number of cases is low for accurate description so the relationship between the timing of ambulation and PDPH needs more cases than our study to interpret.

\section{Conclusion}

Overall, we concluded that when performing spinal anesthesia for cesarean section, 27G Quincke needle has no advantages to $25 \mathrm{G}$ Quincke needle in frequency and severity of post-dural headache.

\section{Ethical Issues}

Approval was obtained from the Local Ettics Committee and written informed concent was received from the patients.

\section{Finnacial Support}

None declared.

\section{Conflict of Interests}

The authors declare that they have no conflict of interests.

\section{Acknowledgments}

The authors are grateful to the Obstetricians of Alzahra Hospital for their cooperation.

\section{References}

1. Chestnut DH, Wong CA, Tsen LC, Ngan Kee DW, Beilin Y, Mhyre. Chestnut's Obstetric Anesthesia: Principles and Practice. 5th ed. Saunders; 2014.

2. Kuczkowski KM. Post-dural puncture headache in the obstetric patient: an old problem. New solutions. Minerva Anesthesiol. 2004;70:823-830.

3. Kuczkowski KM. The spinal headache in pregnant women. NJ Obest Gynaecol. 2006;1:4-19. dio:10.3126/ njog.vLi2.1486.

4. Tumbull DK, Shepherd DB. Post-dural puncture headache: pathogenesis, prevention and treatment. Br J Anesth. 2003;91(5):718-729.

5. Ghaleb A. Postdural puncture headache. Anesthesiol Res Pract. 2010;2010: 102967. dio:10.1155/2010/102967.

6. Leybecker H, Moller JT, May O, Nielsen HK. Incidence and prediction of postdural puncture headache. A prospective study of 1021 spinal anesthesias. Anesth Analg. 1990;70(4):389-394.

7. Vallejo MC, Mandell GL, Sabo DP, Ramanathan 
S. Postdural puncture headache: A randomized coparison of five spinal needles in obstetric patients. Anesth Analg. 2000;91(4):916-920.

8. Miller Ronald D, Eriksson LI, Fleisher L, WienerKroenish PJ, Young WL. Miller's Anesthesia. 7th ed. Churchill Livingstone; 2010.

9. Tajavanija S, Sithinamsuwan P, Sthinvamuswan N, Nidhinandana S, Suwantamee J. Comparison of prevalance of post-dural puncture headache between six hour supine recumbence and early ambulation a after lumbar puncture in thai patients: a randomized controlled study. J Med Assoc Thai. 2006;(6):814-820.

10. Kuzkowski KM. Decreasing the incidence of post-dural puncture headache: an update. Acta Anesthesiol Scand. 2005;49(4):594. dio:10.1111/ j.1399-6576.2004.00562.x.

11. Kang SB, Goodnough DE, Lee YK, et al. Comparison of 26- and $27 \mathrm{G}$ needles of spinal anesthesia for ambulatory surgery patients. Anesthesiology. 1992;76(7):734-738.
12. Shaikh JM, Memon A, Memon MA, Khan M. Postdural puncture headache after spinal anesthesia for caesarean section: a comparison of $25 \mathrm{~g}$ Quincke, $27 \mathrm{~g}$ Quincke and $27 \mathrm{~g}$ Whitacre spinal needles. J Ayube Med Coll Abbottabad. 2008;20(3):10-13.

13. Armon C, Evans RW. Therapeutics and thechnology assessment subcommittee of the American Academy of Neurology. Addendumto assessment: prevention of post-lumbar puncture headaches: report of the American Academy of Neurology. neurology 2005;65(4):510-512. dio:10.1212/ o1.wnl0000173034.96211.1b.

14. Lambert DH, Hurley RJ, Hertwing L, Datta S. Role of needle gague and tip configuration in the production of lumbar pancture headache. Reg Anesth. 1997;22(1):66-72.

15. Shah A, Bhatia PK, Tulsiani KL. Postdural puncture headache in caesarean section: A comparative study using 25G Quincke, 27G Quincke and 27G Whitacre Needles. Indian J Anesth. 2002;46(5):373-377.

Copyright (C) 2015 The Author(s); This is an open-access article distributed under the terms of the Creative Commons Attribution License (http://creativecommons.org/licenses/by/4.0), which permits unrestricted use, distribution, and reproduction in any medium, provided the original work is properly cited. 